\title{
Parents Shape their Children's Physical Activity During Unstructured Recess Through Intrinsic Value the Children
} Possess

\author{
Yangyang Deng ${ }^{a, *}$, Yongju Hwang ${ }^{b}$, Todd Layne ${ }^{b}$, and Sami Yli-Piipari ${ }^{b}$ \\ a Department of Sport pedagogy, University of Georgia, Georgia, 30602. \\ ${ }^{b}$ Department of Health and Sport Sciences, University of Memphis, Memphis, TN 38152, United States. \\ *Corresponding author Email: yd97674@uga.edu \\ DOI: https://doi.org/10.34256/ijpefs21311 \\ Received: 01-07-2021, Revised: 24-09-2021; Accepted: 26-09-2021; Published: 30-09-2021
}

Abstract: Parents beliefs processes has shown to relate to their children's decisions making. Thus, grounded in the expectancy-value theory, the aim of this study was to examine parents' role in shaping elementary school students' beliefs and task values toward students' school-time physical activity (PA) and their moderate-to-vigorous (MVPA) behavior during unstructured recess. A convenience sample of 115 ( $\left.M_{a g e}=10.12 \pm 1.81\right)$ children and their parents/guardians were recruited, and their expectancy-beliefs and attainment, utility, and interest values toward school-time PA were assessed. In addition, children's MVPA during recess was measured using waist-attached accelerometers. Results showed that parents impacted children's recess PA in different ways depending on children's gender. In girls, parents' beliefs and values transferred directly to the subsequent values of their children, whereas parents' beliefs were the central predictors of boys' beliefs and values. Parents' intrinsic value moderated girls' MVPA via the intrinsic value of the participants possessed $(Z=1.73, p=.010,90 \%$ CI $[.36$, 2.93]), whereas parents' beliefs moderated boys' intrinsic value - MVPA relationship $(Z=.78, p<.001,90 \% \mathrm{CI}$ $[.39,1.10])$. This study suggests applying gender-specific strategies when trying to understand how beliefs and task values impact PA-related behaviors.

Keywords: Expectancy belief, Task value, Motivation

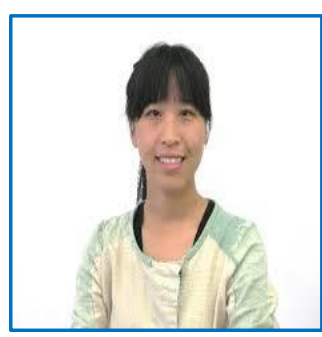

Yangyang Deng is a Ph.D. candidate in sport pedagogy at the University of Georgia. She received the 2018 American Kinesiology Association Master's Scholar at the University of North Carolina at Greensboro. Her interests including youth' and college student's physical activity and fitness, adolescents' lifelong health physical activity behavior, and longitudinal research designs and methodology.

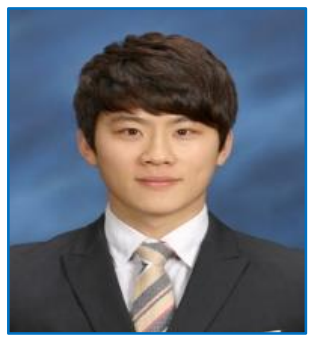

Yongju Hwang is a last year Ph. D student majoring in physical education in the Department of Education at the University of Georgia and the lab manager of the Children's Physical Activity and Fitness Laboratory's (CPAF). His research interests include effective teaching to promote motivation and physical activity in physical education and sports.

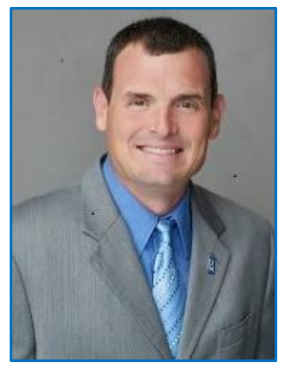

Dr. Todd E. Layne is an Associate Professor of Physical Education Teacher Education in the School of Health Sciences at The University of Memphis. He received his B.S. and M.A. in Health and Physical Education from Tennessee Technological University and his Ph.D. in Physical Education from Auburn University. His research program examines the use of the Sport Education curriculum model. Primary interests involve examining the use of Sport Education with children in the primary grades and university setting with a focus on teacher effectiveness, student competence and skill development. Other interests include examining high 
autonomy climates and the impact on student learning and student physical activity levels. In addition, he has begun examining the use of Adaptive Learning in higher education and Sport Coaching. Interest in Sport Coaching include coach emotion, positive pedagogy, and instructional practices. His work has been published in peer-reviewed journals, such as the Journal of Teaching in Physical Education, Physical Education and Sport Pedagogy, and European Physical Education Review. He has also made several presentations at academic conferences, such as the Society of Health and Physical Educators (SHAPE America).

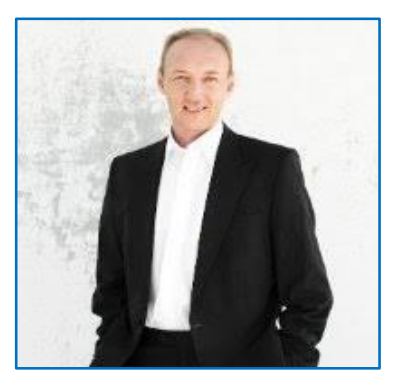

Dr. Sami Yli-Piipari is an associate professor of Kinesiology at the University of Georgia, and he directs Children's Physical Activity and Fitness Laboratory. He is a children and adolescent physical activity specialist with an academic interest in motivational processes impacting sustainable physical activity and exercise behaviors. Specifically, he is examining how educational physical activity experiences, such as school physical education or community programs, and psychological need-supportive instruction facilitate sustainable physical activity. As an outcome of his study, it is possible to design more effective interventions to impact children's and adolescents' lifelong healthy behaviors.

\section{Introduction}

It is well-established that parental beliefs and value processes have an impact on their children's educational (e.g., educational decisions and aspirations $[1,2]$ and health behaviors (e.g., physical activity [PA], $[3,4])$. For instance, parents' expectancy-related beliefs and values have shown to impact their children's PA-related behaviors, such as PA intentions, persistence, and participation choices through their children's subsequent beliefs and values $[5,6,7]$. However, it is largely unknown how parental motivational processes impact students' motivation to be physically active during school-day, and whether parental motivation has a role in children's actual school-time PA behaviors. Thus, grounded in the expectancy-value theory $[8,9]$, the current study examined parental beliefs and value processes in shaping elementary school students' PA beliefs and task values toward students' school-day PA and their actual PA behavior during unstructured recess.

\subsection{Theoretical Framework}

Numerous theoretical models have been proposed to understand student motivation and PA behavior. One of the most comprehensive models is the expectancy-value theory $[8,10,11]$, which can be used to comprehend parental influences on their children's behaviors in achievement settings. The theory [8] emphasizes two theoretical concepts: expectancy beliefs and task values. Eccles et al. [8] defined expectancy beliefs as individuals' evaluations of their competence in different areas and beliefs about how well they will perform on upcoming tasks. These ability/competence beliefs are similar constructs to Harter's [12] perceptions of competence (i.e., cognitive representations of the level of one's ability) and Bandura's [13] personal efficacy expectations (i.e., individuals' confidence in their ability to organize and execute a given task). However, by combining these dimensions, Eccles et al. [8] specified these expectancy-related beliefs in relation to different tasks or, more broadly, to different contexts. To specify these tasks, Eccles et al. [8] outlined four components of task value: attainment value (i.e., the importance of performing well on the given task), utility value (i.e., how well a task relates to current and future goals), intrinsic value (i.e., enjoyment the individual receives from performing the activity), and cost (i.e., the negative aspects of engaging in the task and the amount of effort needed to succeed). The empirical studies conducted in the PA/sport domain by Eccles and colleagues have focused on the first three of these characteristics $[14,10,11]$. Cost has received less research attention and it is not examined in the present study.

\subsection{Parental Influences on Children's Physical Activity Beliefs and Behaviours}

Children's beliefs and decisions in a school environment are largely influenced by their perception of social environments created by e.g. parents, peers, and teachers [15]. Although all of these factors play an important part in children's beliefs and decisions, the role of parents may be the most important, as they help children interpret experiences and influence their motivation through expectancies and values of specific activities $[2,10]$. For example, on school-day PA (e.g., unstructured recess), the expectancy beliefs and task values parents possess can transmit to their children 
implicitly or explicitly through numerous ways (e.g., suggestions, guidance, and/or reminders to engage in $\mathrm{PA}$ ) [16]. Unstructured school-time recess is an interesting context because it gives children possibilities to either be physically active or inactive without direct parental guidance. A recess differs from out-of-school sports, which in childhood is heavily regulated by parents [17].

Research has shown parents' expectancies for their children to be associated with their children's expectancies for success in educational outcomes [2]. For example, if parents believe that their children will do well in mathematics and science tasks, their children will have high expectations toward those subjects [14]. Similarly, Fredricks and Eccles [18] found a positive relationship between parents' perceptions of the importance and usefulness of sport participation and their children's perceptions of their own competence and the value they placed on their own sports participation. In addition, parents' values have shown to be positively correlated with children's perceptions of their physical competence in fitness [19]. Consistent with the previous findings, research has shown children whose parents placed value (i.e., attainment and utility) on their participation in a running program to be likely to exert greater effort and to perform better compared to the children whose parents do not value a running program [20]. In summary, previous findings have supported the central tenets of the expectancy-value theory and highlighting the role of parents' beliefs and values in shaping their children's expectancy-related values in PA.

\subsection{Expectancy Beliefs, Task Values, and Physical Activity}

The expectancy-value theory postulates that expectancy beliefs and task values mediate relationships between social environment and behavioral outcomes [21, 10]. The findings have shown that expectancy beliefs and task values are crucial factors in predicting children's and adolescents' effort, persistence, participation, performance, and choices in sport and PA $[5,7,20,22]$. A meta-analysis [23] suggests that expectancy beliefs and task values are two effective motivators in $\mathrm{K}-12$ physical education. Research has shown expectancy beliefs and intrinsic values to predict middle school students' performance in school physical education [22], and expectancy beliefs have shown to be positively related to effort and persistence in basketball [5] and cardiovascular fitness tasks [24]. Xiang and colleagues [20], on the other hand, found expectancy beliefs to be predictors of students' persistence and performance in a one-mile run, whereas interest and attainment values were predictors of their intention for future participation in the running program and PA in general.

Previous studies indicate gender differences in participants' expectancy-related beliefs and values [25, $26,4]$. Research has consistently shown boys have higher expectancy beliefs toward PA, sports, and physical education [7, 14, 26, 22]. Similarly, it has been reported that, compared to girls, boys place higher importance on participating in sport $[27,18,14]$ and physical education [4, 22] Yli-Piipari and Kokkonen [22] found middle school boys' intrinsic values and girls' attainment values to predict their engagement in physical education. In addition, when examining the predictive strength of physical education values on participants' future PA, boys' interest value was found to be a sole predictor, whereas for girls all three values predicted their PA [4]. On the contrary, several studies have reported no gender differences in the values of physical education and sport activities $[25,20]$.

\subsection{The Present Study}

Building on the findings of the previous studies, the primary purpose of this study was to examine parents' role in shaping elementary school students' PA beliefs and task values towards schooltime PA. Specifically, the first aim of the study was to examine elementary school-aged children's expectancy beliefs and values toward school-time PA and MVPA behavior during unstructured recess. First, we hypothesized that boys will have higher expectancy beliefs and values toward school-time PA compared to girls, and boys will have more MVPA than girls (Hypothesis 1a). Second, we hypothesized that intrinsic values for boys and all three values for girls would predict their MVPA (Hypothesis 1b). In addition, the second aim of the study was to examine the role of parents' beliefs and values in their children's PA behavior during unstructured school recess. It was hypothesized that parents' expectancy beliefs and attainment and intrinsic and utility values would moderate children's MVPA during recess (Hypothesis 2).

\section{Materials and Methods}

\subsection{Participants}

A sample of 115 elementary school students (61 girls, 54 boys, Mage $=10.12 \pm 1.81$; racial make-up: 42\% White, 37\% Black, 26\% Hispanic, and 10\% 
Asian) and their parents from one inner-city public school located in the Southeastern US was recruited. Recess area was a mid-size space (concrete and grass) and a playground area equipped with traditional playground fixtures. An Institutional Review Board permission, parental consents, and student assents were collected prior to the study.

\subsection{Procedures}

Classroom teachers collected questionnaire data under surveillance of researchers during participants' normal homeroom time. Due to the young age of the child participants, their classroom teacher read out loud each statement (one by one), and the participants were requested to initiate their agreement selecting the most suitable smiley face from the 5point smiley face Likert-scale. Parent questionnaires were mailed to the parents, with a request to return the questionnaires using the pre-stamped envelope in one week. PA data were collected during unstructured recess. Data were recorded as actual, not intended, PA. In other words, if children were released to the recess early/late, their actual PA was recorded.

\subsection{Measures}

\subsubsection{Children's Expectancy Beliefs and Values} Toward School-Day Physical Activity

Participants' expectancy beliefs towards school-time PA was measured using the SelfPerception Questionnaire [28, 29]. The responses were collected using a 5-point smiley face Likert scale. The questionnaire was based on the conceptualizations of Eccles et al. [8] with modifications appropriate to the school-day PA context. Three questions measuring children' expectancy-related beliefs (e.g., "compared with other kids my age, I am very active in school") and two questions each addressing their attainment value (e.g., "Being physically active during school day is important for my health"), utility value (e.g., "In general, school-time physical activity is very useful"), and intrinsic value (e.g., "I like being physically active during school day"). This scale has been shown to have acceptable validity and reliability [25].

\subsubsection{Parents' Expectancy Beliefs and Values Toward School-Day Physical Activity}

Parents were asked to respond to the questionnaire adopted from the work of Eccles et al. [8] measuring their expectancy beliefs and values towards PA. First, the stem for the items will be "think about your experience with your child's school as you read each statement below." Three questions measuring parents' expectancy-related beliefs (e.g., "compared to other students, my children are physically active in school") and three questions each taping their attainment value (e.g., "School-day PA is important for my child's health"), utility value (e.g., compared to academic education, school day PA is equally important"), and intrinsic value (e.g., "in general, my child finds PA fun"). A 5-point Likert scale ( 1 = strongly disagree...5 = strongly agree) was be used. Eccles and Wigfield [28] have demonstrated high reliability and validity of the scale in a series of studies of elementary and middle school students.

\subsubsection{Recess Physical Activity}

Students' PA during unstructured recess was measured using ActiGraph GT3X+ accelerometers attached to participants' waist. Accelerometer data were collected using the measurement protocol with a frequency of $30 \mathrm{~Hz}$ with the 10 -second epoch count conversion. The cut-points larger than 2,296 cpm were used as thresholds for MVPA engagement.

\subsection{Data Analysis}

Statistical analyses were performed in the following procedures. Preliminary analyses included calculating descriptive statistics, such as means, standard deviations, Pearson's correlation coefficients, intra-class correlations, and Cronbach's alphas for internal consistency. In addition, the construct validity of parents' and children's scales was estimated using confirmatory factor analyses. To avoid model saturation, we implemented the entire expectancyvalue model (Figure 1) in the analyses. To examine parents' role in elementary school students' beliefs, values, and MVPA, a path model was set up following the theorization of Eccles and Wigfield [8]. MVPA was placed as a dependent variable and regressive paths from students' expectancy-beliefs and attainment, intrinsic and utility values were set to the outcome variables. In addition, parents' expectancy beliefs and attainment, intrinsic and utility value were regressed to the subsequent students' beliefs and task values. All the student level variables were allowed to correlate. Next, acknowledging the general trend that has shown children's and adolescents' expectancy beliefs and values toward school subjects, PA, and sports decline across age $[18,11]$ grade was set as a covariate with regressive path on children's expectancy belief and value variables and MVPA to account for this possible effect. 


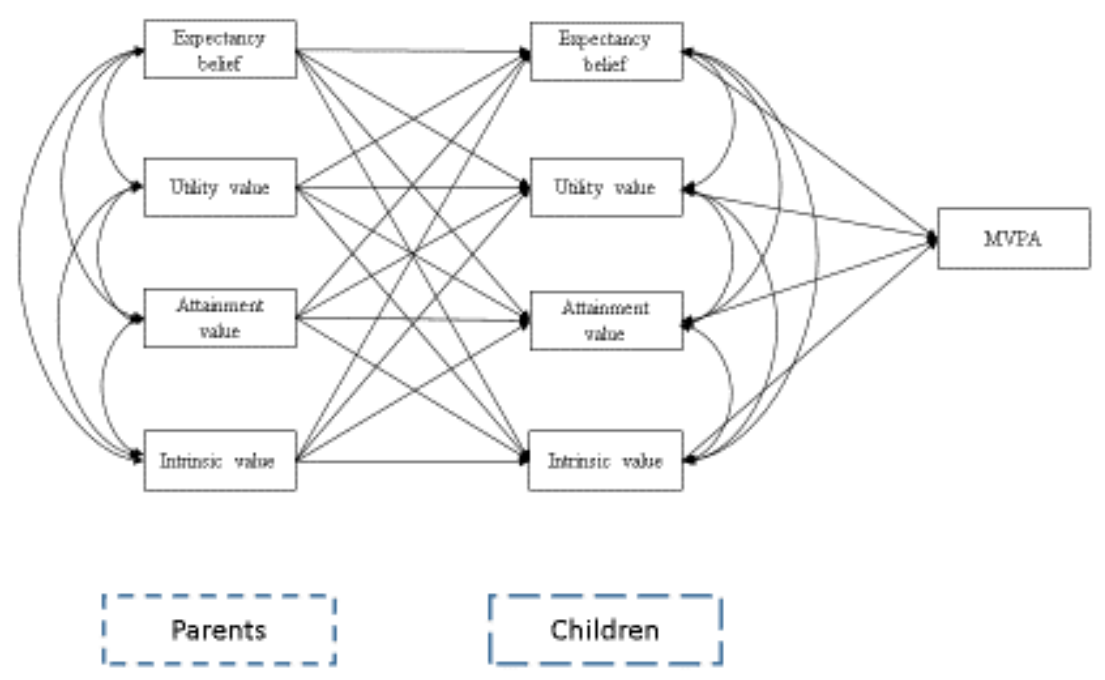

Figure 1. Illustration of the simplified expectancy value theory as it relates to the current inquiry

Note 1 . All the theory-based relationships are assumed to be positive. Note 2 . The covarying effects from grade to child-level variables are omitted from the figure for clarity.

Finally, similar models were estimated for both genders. The descriptive analyses were performed using the SPSS (version 25) and the path confirmatory factor and path analyses with Mplus (Version 7.1) [30]. Alpha was set at $p<.05$ for all tests. Standardized mean changes were calculated, with values of .2 (small), .5 (moderate), and .8 (large) used as guidelines for interpreting analyses of covariance effect sizes [31]. A model fits the data well when the $p$-value associated with the chi-square test is non-significant. In addition, if the values of the Bentler comparative fit index (CFI) [32] and Tucker-Lewis index (TLI) [33] are above .95 and the values of the Root Mean Squared Error of Approximation (RMSEA) are below .06, a good fit between the hypothesized model and the observed data exists $[32,33]$. Moderating effects were tested using the established guidelines for Mplus, with the maximum likelihood model estimator and 10,000 bootstrapped estimates [34].

\section{Results}

\subsection{Descriptives}

Table 1 presents Pearson's correlation coefficients, means, standard deviation, Cronbach's alphas, and intra-class correlations. Cronbach's alpha values showed acceptable internal consistency of the scales. The parents' beliefs and task values are positively related to students' beliefs and task values. The parents and students reported relatively high expectancy beliefs and task values (ranging from $3.82 \pm .78$ for parents' beliefs to $4.48 \pm .65$ for parents' utility value). The students participated on average in light to moderate recess PA (5.81min \pm 2.02$)$. Parents' beliefs and task values positively correlated with each other. Results of the confirmatory factor analyses showed that the scales had an acceptable factorial validity (See Table 2)

\section{Hypothesis 1a: Gender differences}

The analyses showed no statistically significant gender differences in expectancy beliefs $(t(113)=.49$, $p=-.834)$, attainment value $(t(113)=-.072, p=$ $.891)$, utility value $(t(113)=-.46, p=.849)$, or intrinsic value $(t(113)=-.93, p=.135)$. The analyses showed no statistically significant gender differences in MVPA $(t(113)=3.78, p=.054)$. Similarly, there were no statistically significant grade level differences in the MVPA during recess $(f(3,111)=.86, p=.466)$.

Hypothesis 1b: Predictive strength of parents' and children's expectancy beliefs and values on children's MVPA

To answer the second research question, the path analyses were conducted to predict MVPA from parents' expectancy beliefs and different value dimensions (attainment, intrinsic and utility) via students' expectancy beliefs and values. In addition, parents' expectancy belief and value dimensions as well as students' beliefs and values were allowed to correlate, and grade was set as a covariate. The fit of models was within acceptable limits: $\mathrm{X} 2(8)=7.00, p=$ $.136, \mathrm{CFI}=.98, \mathrm{TLI}=.84, \mathrm{RMSEA}=.081,90 \% \mathrm{CI}$ $(.00, .18)$. The results are presented in Table 2, including the relationships within the theorized model. 
The examination of the gender specific models is presented in Figure 2. The fit of both models was within acceptable limits: the girls' model $X 2(8)=5.93$, $p=.205, \mathrm{CFI}=.99$, TLI $=.95, \mathrm{RMSEA}=.060,90 \% \mathrm{CI}$ $(.00, .11)$ the boys' model $\mathrm{X} 2(8)=15.91, p=.003$, CFI $=.98$, TLI $=.94$, RMSEA $=.059,90 \%$ CI $(.00$, .10). On the covariate effect, grade had a weak effect on attainment and intrinsic values (older girls valued school-time PA more than younger girls) and on MVPA (younger boys were more physically active than older boys). The results showed that parents' beliefs predicted girls' beliefs $(\beta=.41)$ and boys' utility values $(\beta=.58)$, attainment values $(\beta=.43)$ and intrinsic value $(\beta=.51)$. Parents' attainment value predicted

Table 1. Summary of Pearson's Intercorrelations, Means, Standard Deviations, and Cronbach's Alpha Coefficients for all Variables

\begin{tabular}{|c|c|c|c|c|c|c|c|c|c|c|c|}
\hline Variable list & 1 & 2 & 3 & 4 & 5 & 6 & 7 & 8 & 9 & $a$ & ICC \\
\hline 1 Parents beliefs & - & & & & & & & & & .90 & na \\
\hline $\begin{array}{l}2 \text { Parents' attainment } \\
\text { value }\end{array}$ & $.42 * *$ & - & & & & & & & & .88 & na \\
\hline 3 Parents' utility value & $.21 *$ & $.70 * *$ & - & & & & & & & .86 & na \\
\hline $\begin{array}{l}4 \text { Parents' intrinsic } \\
\text { value }\end{array}$ & $.48^{* *}$ & $.58^{* *}$ & $.51^{* *}$ & - & & & & & & .88 & na \\
\hline 5 Beliefs & $.44 * *$ & $.61^{* *}$ & $.42 * *$ & $.37 *$ & - & & & & & .92 & .012 \\
\hline 6 Attainment value & $.28 * *$ & $.27 * *$ & $.19 *$ & $.21^{*}$ & $.36 * *$ & - & & & & .91 & .007 \\
\hline 7 Utility value & $.37 * *$ & $.19 *$ & $.23 *$ & $.33 * *$ & $.42 * *$ & $.65^{* *}$ & - & & & .93 & .006 \\
\hline 8 Intrinsic values & $.41^{*}$ & $.33 * *$ & .12 & $.38^{* *}$ & $.39 * *$ & $.53 * *$ & $.68^{* *}$ & - & & .90 & .015 \\
\hline 9 MVPA & $.29 * *$ & $.32 * *$ & $.45^{* *}$ & $.50 * *$ & $.315^{* *}$ & .18 & .06 & .12 & - & na & .016 \\
\hline M & 3.82 & 4.48 & 4.15 & 4.43 & 4.32 & 4.34 & 4.43 & 4.38 & 5.81 & & \\
\hline$S D$ & .78 & .65 & .77 & .74 & .84 & .88 & .80 & .98 & 2.02 & & \\
\hline
\end{tabular}

Note 1. $\mathrm{p}$ values $*<.05, * *<.001 ; \mathrm{a}=$ Cronbach's alpha; ICC $=$ class-level intra-class correlation.

Note 2. Parents and students' beliefs and values' means and standard deviations in the horizontal columns, as for internal consistency internal consistency are presented in the vertical column

Table 2. Confirmatory Factor Analysis Testing for Construct Validity of the Expectancy-Value Theory -Related Scales

\begin{tabular}{lccccc}
\hline \multicolumn{1}{l}{ Measures } & \multicolumn{1}{c}{$\mathrm{X}^{2}(\mathrm{df})$} & RMSEA $(90 \% \mathrm{CI})$ & TLI & $p$ \\
\hline \multicolumn{2}{l}{ Parents Expectancy Value Model } & & & & \\
Females & $.89(48)$ & $.390(.09, .54)$ & .96 & .95 & $<.001$ \\
Males & $154.63(48)$ & $.553(.49, .78)$ & .95 & .93 & $<.001$ \\
Children's Expectancy Value Model & & & & \\
Girls & $111.99(48)$ & $.450(.18, .71)$ & .95 & .95 & $<.001$ \\
Boys & $148.18(48)$ & $.512(.24, .65)$ & .95 & .94 & $<.001$ \\
\hline
\end{tabular}

girls' beliefs $(\beta=.45)$, attainment value $(\beta=.36)$ and utility value $(\beta=.46)$ values, and boys' attainment value $(\beta=.36)$. In addition, parents' utility value

negatively predicted girls' utility value $(\beta=-.29)$ and intrinsic value $(\beta=-.35)$. However, parents' utility value predicted boys' attainment value $(\beta=.37)$. In value $(\beta=.37)$, and intrinsic value $(\beta=.46)$ and boys' beliefs $(\beta=.51)$. Both genders' intrinsic value (girls' $\beta$ $=.61$, boys' $\beta=.61$ ) predicted their actual PA behavior during school recesses. The $R^{2} \mathrm{~s}$ are presented in Figure 2. addition, parents' intrinsic value predicted girls' utility 

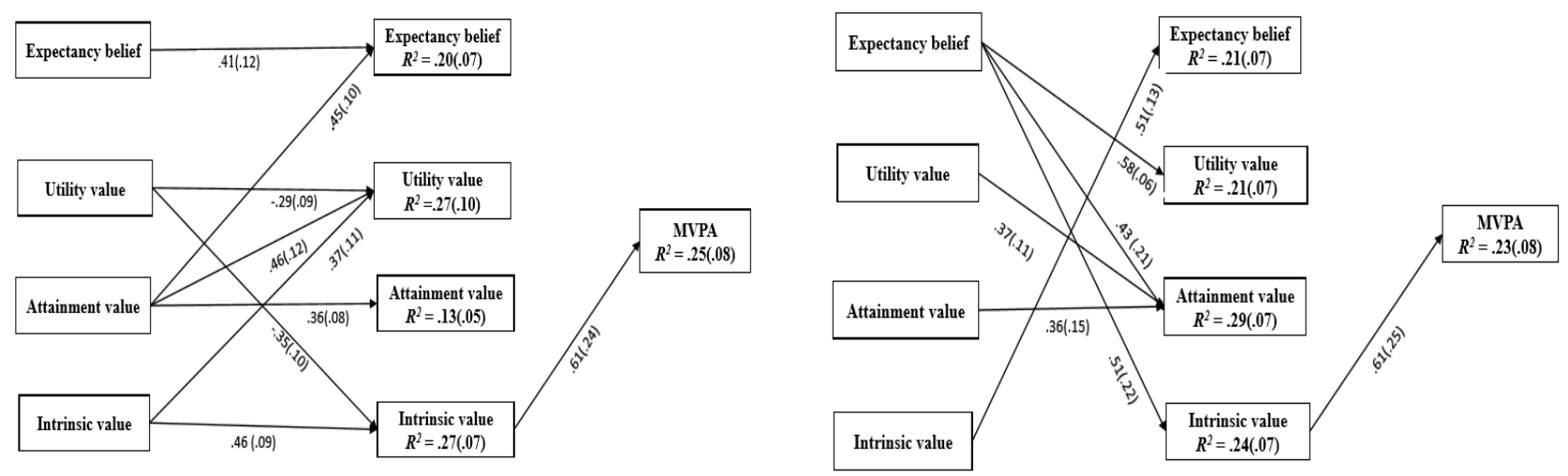

\section{Parents}

Girls

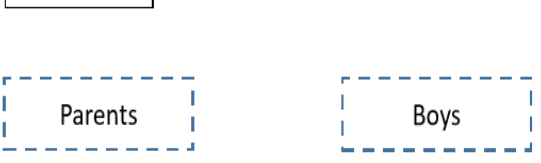

Figure 2. Gender-specific models illustrating statistically significant regressive paths

Note. In the model grade levels was controlled by including a regressive path from grade level to all study variables. Those paths are excluded from this illustration for clarity purposes but presented in Table 3.

Table 3 Regression, Covariate, and Correlation Coefficients for the Path Models

\begin{tabular}{lllll}
\hline Parameter Estimates & \multicolumn{3}{c}{ Girls } \\
& $\begin{array}{l}\text { Unstandardi } \\
\text { zed Values } \\
(\beta)\end{array}$ & $\begin{array}{l}\text { Standardized } \\
\text { Values }(\beta)\end{array}$ & $\begin{array}{l}\text { Unstandardize } \\
\text { d Values }(\beta)\end{array}$ & $\begin{array}{l}\text { Standardiz } \\
\text { Values }(\beta)\end{array}$ \\
\cline { 2 - 5 } Regression Coefficients & & & & \\
Parents Bel -> Bel & $.36(.11)^{*}$ & $.41(.12)^{*}$ & $.17(.16)$ & $.17(.17)$ \\
Parents Bel -> Att & $.22(.15)$ & $.24(.17)$ & $.37(.18)^{*}$ & $.43(.21)^{*}$ \\
Parents Bel -> Uti & $.16(.09)$ & $.13(.08)$ & $.45(.18)^{*}$ & $.58(.06)^{*}$ \\
Parents Bel -> Int & $.13(.07)$ & $.21(.12)$ & $.47(.18)^{*}$ & $.51(.22)^{*}$ \\
Parents Uti-> Bel & $.02(.07)$ & $.07(.09)$ & $.08(.10)$ & $.11(.13)$ \\
Parents Uti -> Att & $.01(.07)$ & $.02(.07)$ & $.24(.08)^{*}$ & $.37(.11)^{*}$ \\
Parents Uti -> Int & $-.28(.08)^{*}$ & $-.35(.10)^{*}$ & $.05(.09)$ & $.09(.11)$ \\
Parents Uti -> Uti & $-.22(.07)^{*}$ & $-.29(.09)^{*}$ & $.02(.10)$ & $.06(.14)$ \\
Parents Att-> Bel & $.38(.08)^{*}$ & $.45(.10)^{*}$ & $.02(.10)$ & $.03(.11)$ \\
Parents Att -> Att & $.22(.04)^{*}$ & $.36(.08)^{*}$ & $.25(.13)^{*}$ & $.36(.15)^{*}$ \\
Parents Att -> Int & $.08(.10)$ & $.12(.12)$ & $.01(.10)$ & $.03(.15)$ \\
Parents Att -> Uti & $.38(.10)^{*}$ & $.46(.12)^{*}$ & $.03(.11)$ & $.06(.16)$ \\
Parents Int-> Bel & $.09(.09)$ & $.11(.12)$ & $.38(.11)^{*}$ & $.51(.13)^{*}$ \\
Parents Int-> Att & $.01(.08)$ & $.02((.10)$ & $.01(.11)$ & $.04(.14)$ \\
Parents Int-> Int & $.28(.07)^{*}$ & $.46(.09)^{*}$ & $.09(.11)$ & $.14(.15)$ \\
Parents Int-> Uti & $.25(.08)^{*}$ & $.37(.11)^{*}$ & $.01(.07)$ & $.03(.11)$ \\
Bel-> MVPA & $.01(.16)$ & $.03(.22)$ & $.04(.14)$ & $.08(.26)$ \\
Att -> MVPA & $.02(.16)$ & $.03(.28)$ & $-.05(.19)$ & $-.11(.44)$ \\
Uti -> MVPA & $.12(.17)$ & $.24(.35)$ & $.28(.09)$ & $.71(.42)$ \\
Int -> MVPA & $.41(.18)^{*}$ & $.61(.24)^{*}$ & $.35(.10) *$ & $.61(.25)^{*}$ \\
& & & &
\end{tabular}




\begin{tabular}{|c|c|c|c|c|}
\hline Covariate Coefficients & $\begin{array}{l}\text { Standardize } \\
\text { d Values }(\beta)\end{array}$ & $\begin{array}{l}\text { Unstandardize } \\
\text { d Values }(\beta)\end{array}$ & $\begin{array}{l}\text { Standardized } \\
\text { Values }(\beta)\end{array}$ & $\begin{array}{l}\text { Unstandardize } \\
\text { d Values (B) }\end{array}$ \\
\hline Grade-> Bel & $.15(.09)$ & $.11(.07)$ & $-.07(.11)$ & $-.03(.06)$ \\
\hline Grade-> Att & $.29(.13) *$ & $.22(.11)^{*}$ & $-.08(.12)$ & $-.06(.08)$ \\
\hline Grade-> Uti & $.11(.11)$ & $.03(.14)$ & $-.03(.12)$ & $-.02(.08)$ \\
\hline Grade-> Int & $.25(.08)^{*}$ & $.22(.08)^{*}$ & $-.01(.11)$ & $-.00(.07)$ \\
\hline Grade ->MVPA & $-.12(.11)$ & $-.16(.15)$ & $-.28(.11)^{*}$ & $-.43(.18)^{*}$ \\
\hline Correlation Coefficients & $\begin{array}{l}\text { Standardize } \\
\text { d Values }(z)\end{array}$ & $\begin{array}{l}\text { Unstandardize } \\
\text { d Values }(r)\end{array}$ & $\begin{array}{l}\text { Standardized } \\
\text { Values }(z)\end{array}$ & $\begin{array}{l}\text { Unstandardize } \\
\text { d Values }(r)\end{array}$ \\
\hline Bel - Att & $.13(.08)^{*}$ & $.26(.15)^{*}$ & $.12(.09)$ & $.24(.16)$ \\
\hline Bel - Uti & $.13(.07)^{*}$ & $.36(.12)^{*}$ & $.08(.07)$ & $.18(.16)$ \\
\hline Bel - Int & $.13(.07)^{*}$ & $.25(.14)^{*}$ & $.01(.07)$ & $.02(.15)$ \\
\hline Attainment - Intrinsic & $.17(.08)^{*}$ & $.20(.14)^{*}$ & $.36(.10) *$ & $.58(.19) *$ \\
\hline Attainment - Utility & $.22(.06)^{*}$ & $.48(.09)^{*}$ & $.37(.12)^{*}$ & $.66(.12)^{*}$ \\
\hline Intrinsic - Utility & $.32(.08)^{*}$ & $.72(.07) *$ & $.22(.09) *$ & $.41(.14)^{*}$ \\
\hline
\end{tabular}

Note. P values $*<.05$

Hypothesis 2: Moderating Effects of Parents' Beliefs and Values

The moderator analysis showed that girls' and boys' intrinsic value was moderated by parents' intrinsic value in girls $(Z=1.73, p=.010,90 \% \mathrm{CI}$ $[.36,2.93])$ and parents' expectancy beliefs in boys ( $Z$ $=.78, p<.001,90 \%$ CI $[.39,1.10])$, and it had a statistically significant effect on their MVPA.

\section{Discussion}

The purpose of this study was to examine parents' role in shaping elementary school students' beliefs and task values toward students' school-time PA and their actual, objectively measured MVPA behavior during unstructured recess. First, this study showed that parents and children value school-time PA opportunities. Although the study did not identify any mean level gender differences in beliefs, values, or MVPA, the findings of this study supported the hypotheses and previous studies [4, 22] showing gender differences in the relationship between individuals' value structure and PA behaviors.

\subsection{Gender Differences}

This study extends the previous findings mainly conducted in PA and physical education contexts [7, 22]. Parents' and children's expectancy beliefs, and especially values toward school-time PA, were high. This study did not find any mean level gender differences. This lack of difference was somehow surprising considering the previous, overwhelming evidence that has shown boys have higher expectancy beliefs and intrinsic value toward PA compared to girls [22]. Similarly, the findings of our study contradict the previous findings that have shown boys to be more physically active during recess compared to girls [35]. It is noteworthy, that the context of the study was unstructured recess with no guidance from significant adults (e.g., physical education teachers or coaches) typically supporting PA engagement. Maybe in this kind of context, there are no gender differences in MVPA. Alternatively, it may be that the 20-minute recess was not long enough to record statistically significant gender differences.

\subsection{Parents' and Children's Expectancy Beliefs and Values on MVPA}

Our study supported the previous studies [36, 27] showing that parents have a gender specific influence on their children's expectancy values toward PA. An important finding was that parents' expectancy beliefs and values seem to translate directly to girls' beliefs and values, whereas for boys, this relationship was evident only in attainment value. In addition, the amount of importance parents showed on school-time PA tend to translate to, not only on girls' attainment, but all other values and beliefs. For boys, parents' beliefs about school-time PA was instrumental in their attainment, utility, and intrinsic values, but not on their beliefs. The results highlight parent' beliefs and values influence on boys and girls through different motivational paths. However, it is not clear what factors influence parents' beliefs and tasks values for different activities. Previous research suggests that 
parents' gender stereotype may influence how competently and intensively boys and girls perform and engage in non-gender appropriate activities (i.e., activities that may have been considered as girls' and boys' activities in the past) in sports), but this finding cannot be directly translated to the recess context. It is possible that physical environment is impacting the motivation structure of children indirectly. Scholars have posited that gender differences might be due to the adoption of gender-role stereotypes, which can occur because of children's need to feel socially accepted [37]. For example, boys may be expected to play masculine-typed tasks (i.e., basketball and football), while girls may be expected to participate in different type of tasks, including gymnastics and dance. These socially constructed gender-role stereotypes might impact the belief and value structures. It is likely that these findings of the gender specific roles gave us more questions than answers. Based on the findings of this study, it can be concluded that parents' roles are gender specific, and future studies should take this into account.

Despite this gender specificity in the role parents play in children's motivation structure, our study found gender similarities, showing that only intrinsic value predicted girls' and boys' actual MVPA behavior. This finding is partially supporting our hypothesis, highlighting the importance of intrinsic value structure in PA-related behaviors [4]. This study, however, did not find girls' attainment and utility values to predict their MVPA in recess. It is noteworthy, that the contexts in these two studies were different. In the study by Yli-Piipari et al. [4], expectancy beliefs and values were measured in physical education, whereas in the current study the context was unstructured recess. It is likely that physical education teachers' role in the motivational process is a significant factor. After all, teachers control content and communication in school physical education, whereas, in this study, the environment was truly a free-choice environment. Based on these findings, it is reasonable to assume that although children may value recess in different ways, the internal interest they receive from MVPA in recess may overcome other motives.

\subsection{Moderating Effects of Parents' Beliefs and Values}

This study found that parents' intrinsic value moderated girls' MVPA in recess via the intrinsic value that the participants possessed, whereas parents' beliefs moderated boys' intrinsic value - MVPA relationship. These findings are novel highlighting the unique, gender-specific role of parents in their children's MVPA behaviors during the time period of free choice. Although the research examining the role of parents' motivation in PA is in its infancy, the findings of the current study largely did not corroborate our study hypothesis. In contrast to the findings of Xiang et al. [20] examining beliefs and values toward the one-mile run, not attainment and utility value but intrinsic value contributed to MVPA during school recess. Our findings, however, are consistent with the finding that have shown students who are intrinsically interested toward physical education are also trying harder during physical education lessons [25]. Our study also highlights the role of parents' beliefs and values as moderators of their children's behavior. For girls, parents who perceive PA as interesting will impact their MVPA engagement via girls' intrinsic values. In contrast to boys, parents with high expectancy perceptions influence boys' MVPA through their intrinsic values. Our results indicate that parents' beliefs and values moderate boys' and girls' motivational processes through different pathways, so future studies should examine whether it would be advantageous for the parents to develop gender-specific cues to help children self-regulate their own PA participation.

\subsection{Limitations and Conclusion}

This study had limitations that require caution when interpreting the results. First, this study examined the relationship among variables within a cross-sectional design. Thus, the nature of the significant relationships found among the variables is correlational only. Causality cannot, therefore, be inferred. Second, some studies have found gender effects focusing on differing parental influence on children's beliefs and behaviors. In the present study, preliminary analyses revealed no significant gender or gender by grade difference in children's PA beliefs. Nevertheless, additional research is needed to clarify if and how gender of parent and child might affect the relationship between children's PA beliefs and behaviors.

In conclusion, the findings of this study showed that parents and children value school-time PA opportunities, and parents' beliefs about and values of children's PA opportunities impact their children's PA beliefs and values. Specifically, parents' beliefs and values towards PA transferred directly to the 
subsequent values of their female children, whereas only parents' beliefs predicted boys' beliefs and values. The findings of this study are significant as they help us to understand children's PA motivation during a free-choice situation.

\section{References}

[1] C.S. Rozek, J.S. Hyde, R.C. Svoboda, C.S. Hulleman, J.M. Harackiewicz, Gender differences in the effects of a utility-value intervention to help parents motivate adolescents in mathematics and science, Journal of Educational Psychology, 107 (1) (2015) 195-206. [DOI]

[2] S.D. Simpkins, J.A. Fredricks, J.S. Eccles, Charting the Eccles' expectancy-value model from mothers' beliefs in childhood to youths' activities in adolescence, Developmental Psychology, 48(4) (2012) 1019-1032. [DOI] [PubMed]

[3] J.E. Bois, P.G. Sarrazin, R.J. Brustad, D.O. Trouilloud, F. Cury, Elementary schoolchildren's perceived competence and physical activity involvement: the influence of parents' role modelling behaviours and perceptions of their child's competence, Psychology of Sport and Exercise, 6 (4) (2005) 381-397. [DOI]

[4] S. Yli-Piipari, (2011) The Development of Students' Physical Education Motivation and Physical Activity: a 3.5-year Longitudinal Study Across Grades 6 to 9 (No. 170), University of Jyväskylä, Studies in Sport, Physical Education and Health 170.

[5] A.E. Cox, D.E. Whaley, The Influence of Task Value, Expectancies for Success, and Identity on Athletes' Achievement Behaviors, Journal of Applied Sport Psychology, 16 (2) (2004) 103117. [DOI]

[6] J.S. Eccles, A. Wigfield, U. Schiefele, (1998) Motivation to Succeed, Handbook of Child Psychology, Wiley, New York, US.

[7] Z. Gao, \& P. Xiang, College students' motivation toward weight training: An application of expectancy-value model, Journal of Teaching in Physical Education, 27 (3) (2008) 399-415. [DOI]

[8] J.S. Eccles, T.F. Adler, R. Futterman, S.B. Goff, C. M, Kaczala, J. L. Meece, C. Midgley, (1983) Expectancies, Values and Academic Behaviors, Achievement and Achievement Motives, WH Freeman, San Francisco, US.

[9] J.S. Eccles, \& A. Wigfield, Motivational beliefs, values, and goals, Annual Review of Psychology,
53 (1) (2002) 109-132. [DOI]

[10] A. Wigfield, J.S. Eccles, Expectancy-value theory of achievement motivation, Contemporary Educational Psychology, 25(1) (2000) 68-81. [DOI] [PubMed]

[11] Wigfield, \& J.S. Eccles, The development of competence beliefs, expectancies for success, and achievement values from childhood through adolescence, Development of Achievement Motivation, (2002) 91-120. [DOI]

[12] S. Harter, (1998) The Development of SelfRepresentations, In W. Damon \& N. Eisenberg (Ed.), Handbook of Child Psychology: Social, Emotional, and Personality Development. John Wiley \& Sons, Inc, PLACE, US. (553-617)

[13] A. Bandura, W.H. Freeman, \& R. Lightsey, (1999) Self-efficacy: The Exercise of Control, Freeman, New York, US.

[14] J.E. Jacobs, J.S. Eccles, The impact of mothers' gender-role stereotypic beliefs on mothers' and children's ability perceptions, Journal of Personality and Social Psychology, 63 (6) (1992) 932. [DOI]

[15] J. Eccles, (1984) Sex Differences in Achievement Patterns, In Nebraska Symposium on Motivation, University of Nebraska Press, Nebraska, US.

[16] Johnston, L. Belschner, J.L. Park, \& K. Stewart, A. Noyes, M. Schaller, Mothers' implicit and explicit attitudes and attributions in relation to self-reported parenting behavior, Parenting, 17 (1) (2017) 51-72. [DOI]

[17] R.J. Brustad, Integrating Socialization Influences into the Study of Children's Motivation in Sport, Journal of Sport and Exercise Psychology, 14 (1) (1992) 59-77. [DOI]

[18] J.A. Fredricks, \& J.S. Eccles, Children's competence and value beliefs from childhood through adolescence: growth trajectories in two male-sex-typed domains, Developmental Psychology, 38 (4) (2002) 519. [DOI] [PubMed]

[19] J.C. Kimiecik, \& A.T. Harris, What is enjoyment? A conceptual/definitional analysis with implications for sport and exercise psychology, Journal of Sport and Exercise Psychology, 18 (3) (1996) 247-263. [DOI]

[20] P. Xiang, R.E. McBride, \& A. Bruene, Fourth graders' motivation in an elementary physical education running program, The Elementary School Journal, 104 (3) (2004) 253-266. [DOI]

[21] D.H. Schunk, J.R. Meece, P.R. Pintrich, (2012) Motivation in Education: Theory, Research, and Applications, Pearson/Merrill, Upper Saddle 
River, US.

[22] S. Yli-Piipari, \& J. Kokkonen, An application of the expectancy-value model to understand adolescents' performance and engagement in physical education, Journal of Teaching in Physical Education, 33 (2) (2014) 250-268. [DOI]

[23] S. Chen, A. Chen, \& X. Zhu, Are K-12 learners motivated in physical education? A metaanalysis, Research Quarterly for Exercise and Sport, 83 (1) (2012) 36-48. [DOI] [PubMed]

[24] Z. Gao, Perceived competence and enjoyment in predicting students' physical activity and cardiorespiratory fitness, Perceptual and Motor Skills, 107 (2) (2008) 365-372. [DOI] [PubMed]

[25] Z. Gao, Students' motivation, engagement, satisfaction, and cardiorespiratory fitness in physical education, Journal of Applied Sport Psychology, 21 (S1) (2009) S102-S115. [DOI]

[26] P. Xiang, R. McBride, J.Guan, M. Solmon, Children's motivation in elementary physical education: An expectancy-value model of achievement choice, Research Quarterly for Exercise and Sport, 74 (1) (2003) 25-35. [DOI] [PubMed]

[27] J. Eccles, A. Wigfield, R.D. Harold, P. Blumenfeld, Age and gender differences in children's self-and task perceptions during elementary school, Child development, 64 (3) (1993) 830-847. [DOI] [PubMed]

[28] J.S. Eccles, \& A. Wigfield, In the mind of the actor: The structure of adolescents' achievement task values and expectancy-related beliefs, Personality and Social Psychology Bulletin, 21 (3) (1995) 215-225. [DOI]

[29] Z. Gao, M. Kosma, \& Jr, L. Harrison, Ability beliefs, task value, and performance as a function of race in a dart-throwing task, Research quarterly for exercise and sport, 80 (1) (2009) 122-130. [DOI] [PubMed]

[30] L.K. Muthén, B.O. Muthén (1998 - 2010), Mplus user's guide 6th edition, Authors, Los Angeles, US.

[31] J. Cohen, (1988) Statistical Power Analysis for the Behavioral Sciences (2nd ed), Lawrence Erlbaum, Hillsdale, NJ.

[32] J. F Hair, W. C Black, B. J Babin, R. E Anderson (2010) Multivariate Data Analysis: Global Perspective (7th ed.), Pearson Education, Upper Saddle River, US.

[33] Z. Awang, (2012) Structural equation modeling using AMOS graphic, Penerbit Universiti
Teknologi MARA.

[34] C.B. Stride, S. Gardner, N. Catley, F. Thomas, (2015) Mplus code for mediation, moderation, and moderated mediation models, Retrieved from

http://www.offbeat.group.shef.ac.uk/FIO/model $\underline{\mathrm{s} \text { and index.pdf }}$

[35] A. Beighle, C.F. Morgan, G. Le Masurier, R.P. Pangrazi, Children's physical activity during recess and outside of school, Journal of School Health, 76 (10) (2006) 516-520. [DOI] [PubMed]

[36] J. Eccles, A. Wigfield, R.D. Harold, P. Blumenfeld, Age and gender differences in children's self-and task perceptions during elementary school, Child Development, 64 (3) (1993) 830-847. [DOI] [PubMed]

[37] A.M. Lee, K. Fredenburg, D. Belcher, N. Cleveland, Gender differences in children's conceptions of competence and motivation in physical education, Sport, Education and Society, 4 (2) (1999) 161-174. [DOI]

\section{Acknowledgement}

The author(s) received no financial support for the research, authorship, and/or publication of this article.

\section{Funding}

No funding was received to carry out this study

\section{Authors Contribution}

All the authors equally contributed to this work, read and approved the final version of the manuscript.

\section{Ethics Approval}

Approval sought from the institution ethics committee

\section{Informed Consent}

Written consent obtained from the participants

\section{Conflict of interest}

The Authors have no conflicts of interest to declare that they are relevant to the content of this article.

\section{Does this article screened for similarity? Yes}

\section{About The License}

(C) The Author(s) 2021. The text of this article is open access and licensed under a Creative Commons Attribution 4.0 International License 